\title{
A flexible all-inorganic fuel cell membrane with conductivity above Nafion, and durable operation at $150^{\circ} \mathrm{C}$.
}

\author{
Y. Ansari, T. G. Tucker, W. Huang, I. S. Klein, S.-Y. Lee, J. L Yarger and C. A. Angell* \\ Dept. of Chemistry and Biochemistry, Arizona State University, Tempe, AZ 85287-1604
}

\section{Abstract:}

The search for fuel cell membranes has focused on carbon backbone polymers, among which Nafion seems to best survive the most severe of the degradation mechanisms attack by peroxide radicals. Less attention has been given to inorganic membranes because of their generally inflexible nature and lower conductivity, though some $\mathrm{SiO}_{2}$-Nafion composites have shown improved properties. Nafion dominates, despite needing hydration, which then restricts operation to below $100^{\circ} \mathrm{C}$ (so CO poisoning problems persist). Described herein is a low cost, flexible, and all-inorganic fiberglass reinforced gel membrane with conductivity exceeding that of Nafion at any temperature above $60^{\circ} \mathrm{C}$. Using Teflon fuel cells, maximum currents $>1 \mathrm{Acm}^{-2}$ and OCV of $1.03 \mathrm{~V}$ at $150^{\circ} \mathrm{C}$ are demonstrated. No detectable loss of cell potential was observed over 24 hours during 50 $\mathrm{mAcm}-2$ constant current operation at $120^{\circ} \mathrm{C}$ while, at $150^{\circ} \mathrm{C}$ and maximum power, the degradation rate is intermediate among other high conductivity $\mathrm{H}_{3} \mathrm{PO}_{4}$ - $\mathrm{PBI}$ type membranes. The structure of the membrane is deduced, mainly from ${ }^{29} \mathrm{Si}$ solid state-NMR. The - $115 \mathrm{ppm}$ resonance, which is extreme for $\mathrm{Q}_{4} \mathrm{Si}(0)$ structures, identifies a zeolite-like 
$\mathrm{SiO}_{2}$ network, which is "floppy". ${ }^{31} \mathrm{P}$ and ${ }^{1} \mathrm{H}$ NMR establish nano-permeating $\mathrm{H}_{3} \mathrm{PO}_{4}$ as the source of the exceptional conductivity.

\section{Introduction:}

The thermodynamic advantages of converting chemical fuel energy to mechanical energy by "burning" in electrochemical cells instead of in heat engines, are as difficult to achieve as they are easy to discuss[1-3]. Central to the problem are the energy losses incurred in the reduction of oxygen to water (or hydroxide ion) at the cathode[1] and in the transport of protons from anode to cathode, together with the materials problem of dealing with the intensely reactive peroxide radical generated in the oxygen reduction process[3-5]. The latter problem seems only to be dealt with adequately by the expensive sulfonated polytetrafluoroethylene (i.e. Nafion-type) polymers $[4,5]$ when in the highly hydrated condition also needed to maximize the conductivity $[1,6]$. Unfortunately this high hydration requirement limits the cell operation to temperatures below $100^{\circ} \mathrm{C}$ unless operated under pressure[7], and introduces a major water management problem due to the physics of facile proton transport that requires some 9-10 water molecules to accompany each proton in the passage from anode to cathode. The consequent cathode flooding must be relieved by back-pumping (ref. [8]. reviews water management). The fuel cell powered cars currently under lease-testing on Japanese, European and American roads, are miracles of engineering - and are priced accordingly.

Considering these problems and the need to use highly purified fuels to avoid catalyst poisoning when operating at temperatures below $150^{\circ} \mathrm{C}$, there have been many 
attempts to seek alternative electrolytes capable of operating efficiently at the higher temperatures. Broadly, these divide into high temperature polymer membranes and inorganic proton conductors, though attempts to raise the operating temperature of Nafion membranes by combination with phosphoric acid and polybenzimadazole have been reported $[9,10]$. Also operating temperatures have been raised by incorporation of inorganic components such as silica spheres[11], and zeolitic structures like mordenite[12]. Although moderately successful, none of the latter escape the high cost of the Nafion component.

The most competitive of the higher temperature polymer membranes all involve some form of polybenzimadazole saturated with phosphoric acid, for which a good review has been provided by Bjerrum and coauthors[13]. These will be discussed in more detail later in this paper in relation to the results of the present paper. Some mention should be made of the attempts to use the cations of protic ionic liquids as proton carriers capable of sustaining operating temperatures above $200^{\mathrm{a}} \mathrm{C}$. These may be both inorganic[14] or organic in nature[15]. The incorporation of the latter into sulfonated polyimide membranes with potentially very high service temperatures has been described by Lee et al.[16]

Solid silicophosphate electrolytes produced by sol-gel processes, can have high conductivities $\left(10^{-2} \mathrm{~S} / \mathrm{cm}\right.$ at $\left.20^{\circ} \mathrm{C}\right)$ and have been seen as a viable alternative to Nafion membranes on both cost and temperature range counts[17, 18]. They have the advantage that organic molecules and solid acids may be incorporated into the inorganic networks to vary the properties. However, these membranes suffer from the onset of mechanical fragility during the fabrication process, becoming laced with cracks during escape of the 
water that is released in the curing process[17]. Another example is that by Matsuda et al [19]. The conductivity of their sol-gel derived glassy material reached $10^{-2} \mathrm{Scm}^{-1}$ without the need to add highly hydrated and temperature-sensitive solid acids as in the case of ref.[17]. Unfortunately, of the many studies of such phosphate-derivatized electrolytes, favored for their stability against reduction by hydrogen, we find very few reports of the their actual incorporation into, and testing of, fuel cells. In this respect, the present contribution is unusual. In the comprehensive review by Zhang and Shen[3], little attention is given to phosphate or silicophosphate membranes, though a complex sulfonatederivatized ceramic membrane described by Peled and coworkers[20] is recognized as promising - indeed these latter workers did report fuel cell tests, in addition to favorable conductivities. Despite open circuit voltages (OCVs) that were only $0.8 \mathrm{~V}$, the maximum power outputs obtained were comparable with those we will report below. Many hybrid inorganic (siloxane) - organic phosphinic acid derivatized polymer membranes have been described, e. g. the work of Kato et al.[21], but these never achieve the conductivity levels that are needed and, again, fuel cell tests are rare (perhaps because good fuel cell performance is rare). An exception is the recent work of Zeng et al on $\mathrm{H}_{3} \mathrm{PO}_{4}$ imbibed in mesoporous silica[22]. Although this membrane is inflexible and of limited conductivity, the current and power densities reported $\left(\left(>2 \mathrm{Acm}^{-2}\right.\right.$ and $\left.>500 \mathrm{mWcm}^{-2}\right)$ for single cells are impressive.

The advantages of both the above membrane types, Nafion-like polymers and $>100^{\circ} \mathrm{C}$ stable silicophosphate and mesoporous silica compositions, may be combined if the silicophosphate or siloxy links are introduced in a different manner, viz., starting from the quasi-solid product of the synthetic process used to make the "SiPOH" suspension whose 
outstanding performance, as a liquid electrolyte, we described in a recent contribution[23]. The new material is structurally quite different from the latter suspension, not only in the absence of P-O-Si bonds (as we show in our Discussion), but also in its physical state, which is a flexible solid. By having zero peroxide radical-sensitive $\mathrm{C}-\mathrm{C}$ or $\mathrm{C}-\mathrm{H}$ bonds, it is also distinct from

the familiar elevated temperature membranes involving $\mathrm{H}_{3} \mathrm{PO}_{4}$-saturated polybenzimidazoles and derivatives[13] referred to further below.

In the present contribution we provide conductivity data for this new material and, more importantly, show how the new material can serve as the membrane in simple $\mathrm{H}_{2} / \mathrm{O}_{2}$ fuel cells that can produce stable currents in excess of one $\mathrm{amp} / \mathrm{cm}^{2}$ at temperatures up to at least $150^{\circ} \mathrm{C}[24]$.

\section{Preparation and description of flexible inorganic (gel) material, and membrane.}

When the stable milky suspension that is the liquid electrolyte of ref.[23], is centrifuged for a long period, a thick paste, described as $\mathrm{SiPOH}$, from which most of the unaltered phosphoric acid has been separated, is obtained. The exact composition of $\mathrm{SiPOH}$ is still unknown. It contains silicon in a six coordinated state, according to ${ }^{29} \mathrm{Si} \mathrm{NMR}$ spectroscopy (see below) and the X-ray diffractogram (see SI) indicates high disorder. According to ICP analysis of the material after washing with an unreactive solvent (pentafluoropropanol), it has an Si:P ratio of 1:4. When this paste is reacted with water (in which it dissolves completely), a floppy gel is formed on standing. An example would be the solution of $1.63 \mathrm{~g}$ of paste in $3 \mathrm{~g}$ of distilled water, from which the gel forms in $90 \mathrm{~min}$ or less. The initial gel is a mechanically frail material that shrinks away from a Teflon 
container and strengthens into a rubbery button (Figure 1(b) as water is removed by vacuum oven drying at $40^{\circ} \mathrm{C}$. A modified version of the $\mathrm{SiPOH}$ paste preparation of ref. [23], in which the liberated $\mathrm{HCl}$ is collected in a novel internal chemical trap, is described in the S. I.

\section{Figure 1 here}

The weight loss vs time function for the gel formed from the initial solution of $\mathrm{SiPOH}$, is shown in Figure 1(a). It is seen to be rapid at first, but then to reach a constant mass. The low evaporation temperature was chosen to avoid the formation of any bubbles. In the process, some $90 \mathrm{wt} \%$ of the initial water content is lost.

This flexible material contains little or no free water because heating at $300^{\circ} \mathrm{C}$ is accompanied by a mass loss of only $10 \mathrm{wt} \%$ - and the weight of the dry (now crystalline, but hygroscopic) powdery material remains almost unchanged when the temperature is raised to $600^{\circ} \mathrm{C}$. As an additional measure of its stability, the gel-like material seems to be quite invariant with temperature up to $150^{\circ} \mathrm{C}$ (see Figure 2 below). It has a yellowy color as seen in Figure 1, but is colorless in other preparations. It is translucent rather than transparent, so must have some heterogeneity at the microscopic level. The calcined powder has an XRD pattern (see SI) that cannot be indexed to any known structure, and is distinct from any of the structures seen to result from calcination of the original SiPOH. The Si:P ratio must remain the same as that of the solid acid viz.1:4 except for any excess $\mathrm{H}_{3} \mathrm{PO}_{4}$ retained in the unwashed $\mathrm{SiPOH}$ paste. The detailed structure will be considered in the Discussion section. First we take advantage of the rubbery character to test its potential as a fuel cell membrane material. 


\section{HOT PRODUCTS}

\section{Conductivity, fuel cell commissioning, and testing.}

The conductivity of the SiPOHgel material of Figure 1(b) was measured on a sample cut from the anhydrous flexible button and dried $15 \mathrm{~h}$ in a vacuum oven at $40^{\circ} \mathrm{C}$, before incorporation in the cell. The conductivity was determined using the same piston type cell with stainless steel electrodes, (mild spring compression for good electrode contact, all assembled under dry nitrogen,), used in an earlier study of highly conducting rubbery polymers (protonated polydichlorophosphazenes), details of which are given in the SI. The complex impedance was determined using a Princeton Applied Research (PARSTAT 2273) potentiostat/galvanostat, modulation amplitude of $100 \mathrm{mV}$, and frequencies ranging from $1.0 \mathrm{~Hz}$ to $200 \mathrm{kHz}$, and analysis for dc conductivity was carried out with the usual Nyquist plots.

The results are shown in Figure 2. Comparison is made with data from three separate reports $[1,7,12]$ on Nafion membranes measured under different conditions of hydration and pressure, with pure phosphoric acid from the melted crystal (this work), and with the most highly conducting $\mathrm{H}_{3} \mathrm{PO}_{4} / \mathrm{PBI}$ type membrane we could find (a PBI-Nafion composite, by Li and Scott[25]). The stability of the present sample at temperatures up to $150^{\circ} \mathrm{C}$ is demonstrated by the agreement of data obtained during heating with data taken during subsequent cooling (Figure 2 caption).

Figure 2 here 
The conductivity of the SiPOHgel is seen to exceed the conductivity of all other samples at any temperature above $60^{\circ} \mathrm{C}$. The most impressive comparison is that with $100 \% \mathrm{H}_{3} \mathrm{PO}_{4}$, famous for its anomalous proton conductivity[26-28]. The closest competition by a solid material comes from a phosphoric acid-PBI-Nafion composite. We note that at the highest temperature these conductors are only 1.5 decades from the theoretical (infrared) limit for ionic conductivity $\left(10 \mathrm{Scm}^{-2}[29]\right)$. In consequence of the low water content and the higher operating temperature that is permitted, neither of these solid electrolytes will incur the water management problems that afflict the Nafion membranes[30-37]

A second slice from the button of the pristine SiPOHgel material was tested as a membrane in a sandwich fuel cell of the type used in previous studies, for which details are here provided. The cell is illustrated, in exploded view, in Figure 3.

\section{Figure 3 here}

Data obtained from this crude initial test exceeded our expectations for current density, but showed unsatisfactory OCV values ( $\sim 0.8 \mathrm{~V}$ ) probably due to fuel crossover effects caused by membrane imperfections. Noting the order of magnitude improvements in membrane performance obtained by Liu et al using membrane reinforcing[38], we produced a stronger flexible membrane by incorporating a fiberglass wool filter ((ColePalmer item QR-200 (Toyo Roshi Kaisha Ltd, Japan) 2 mm thick initially) as supporting matrix, as detailed in Figure 1 (b,c) and caption. The improved membrane was placed in the Figure 3 cell assembly between two standard E-Tek electrodes (LT140E-W; $0.5 \mathrm{mgPt} / \mathrm{cm}^{2}$ ) that had been lightly brushed on the contact surface with a drop of $\mathrm{H}_{3} \mathrm{PO}_{4}$ to assist with the 
establishment of the essential gas-catalyst-electrolyte three-phase contact. To aid this process, the assembled cell, prior to testing, was left overnight in a desiccator in the first case (Figures 4 and 5), and in a low humidity drybox in the second case (Figure 6).

During the testing, the cell was left 2-3 hours at each temperature to ensure thermal equilibrium. The temperature of the cell was tracked relative to the oven atmosphere temperature during the test, for any indication of direct burning by fuel crossover. The very pleasing polarization curves obtained using the improved MEA are displayed in Figure 4. The OCV has regained the values obtained with the previous liquid electrolyte cell[23] and, surprisingly, the maximum current now slightly exceeds the $1000 \mathrm{mAcm}^{-2}$ value reported previously for the higher temperature of $226^{\circ} \mathrm{C}$, notwithstanding the thick membrane.

Figure 4 here

Membranes thinner than our $>2 \mathrm{~mm}$ flexible discs would no doubt yield higher currents and powers. Typical polymer membranes for fuel cells are thinner by more than an order of magnitude[25].

Figure 5 here

Although the OCV for our cell is above $1 \mathrm{~V}$ (see Figure 5) the oxygen electrode polarization remains unalleviated, and the current decrease restricts the maximum power 
output from this otherwise impressive new fuel cell to $200 \mathrm{mWcm}^{-2}$. We might hope to increase this with improved cell design to decrease the slope of the Figure 5 plot so that maximum power can be obtained at a higher potential. Refining the membrane by use of thinner supporting structures is an obvious starting point.

\subsection{Durability testing}

To address the question of membrane endurance under load (usually referred to as a degradation rate), we prepared a new membrane using a modified, more controlled, synthetic route than in the initial SiPOH preparation (modified route described in the S.I). The gel (designated SiPOHgel-K) appeared less robust than in the earlier preparation, perhaps as a consequence of less effective drying, but again was well supported by the same glass wool filter. Used in the same cell, Figure 3, but with a smaller cross section active area, maximum power was reached at $187 \mathrm{mAcm}^{-2}$, lower than previously, but quite sufficient for the purpose of endurance testing.

The cell with this membrane was submitted to constant current tests of 24 hour duration (the maximum setting on our Parstat 2273 Advanced Electrochemical System) initially at a current density of $50 \mathrm{mAcm}^{-2}$ at $120^{\circ} \mathrm{C}$ in order to compare with an earlier study[39] using the same cell and the same Etek electrodes, but carried out using $85 \%$ phosphoric acid (liquid) as the electrolyte. The potential at $50 \mathrm{mAcm}^{-2}$ in our cell (see trace 1 of Figure 6) exceeded, by 20\%, that of the earlier study (trace 2), and remained constant over the entire 24 hour run. A further, and more severe, test was conducted at $151^{\circ} \mathrm{C}$ at the current of maximum power, $187 \mathrm{mAcm}^{-2}$. In this case, a noticeable downward 


\section{Figure 6 here .}

drift was detectable after about $12 \mathrm{hr}$, amounting to $\sim 0.01 \mathrm{mV}(\sim 2 \%)$ over the 24 hour period (trace 3 in Figure 6). This, however, is 5 times smaller than that in the corresponding $\mathrm{Li}$ and Scott study with $\mathrm{H}_{3} \mathrm{PO}_{4}$-in-Nafion-PBI membranes[25] whose membrane conductivity was the closest to that of the present membrane that we found in the literature (findings reproduced in Figures 2 and 6). It might be noted, parenthetically, that the cell suffered an unintended excursion to above $200^{\circ} \mathrm{C}$ before being returned to the desired test temperature for which the data in Figure 6 are recorded, evidently without ill effects. We look forward to more extended testing of this promising MEA in collaboration with industrial partners possessing the appropriate equipment.

Finally, we note the likelihood that the very low "free" water content of the membrane (witness Figure 1a) will be accompanied by a reduction in the rate of Pt catalyst corrosion.

\section{Discussion:}

The extraordinary conductivity of this quasi-solid membrane material demands a structural interpretation. Obviously a precise structure cannot be provided for an 
amorphous material but some principal features can be deduced. While we will arrive at our conclusions systematically, below, we wish to stress here that there will prove to be nothing extraordinary to understand or interpret concerning the conductivity mechanisms, beyond what is abundant in the literature on phosphoric acid itself $[26-28,40]$. The reason will be obvious once we have reasoned our way to the conclusion that SiPOHgel is no more than a very successful sequestration of phosphoric acid in a flexible nano-permeated, defect-free but open (amorphous zeolitic) network of pure silica. The mechanical properties will be determined by the supporting fibreglass matrix - which is subject to separate optimizing development. The improvements in Nafion membrane cell performance that can be obtained by supporting matrices[38] were mentioned earlier.

The most helpful diagnostic tool in seeking understanding of the membrane performance is NMR spectroscopy because three of the four elements of our membrane have good NMR nuclei, two of them $\left({ }^{1} \mathrm{H}\right.$ and $\left.{ }^{31} \mathrm{P}\right)$ in natural abundance. X-ray diffraction studies of calcined products, on the other hand, offer only puzzles at this time, because of the bewildering variety of possible Si-P-O and Si-P-O-H structures that are known[41-43] and the fact that the crystalline product of calcination of the rubbery solid of Figure $1 \mathrm{~b}$ has a powder diffraction pattern that is distinct from that of any previously recorded crystal powder pattern. All that can be said at this time is that the structure of the nearest crystal is characterized by a complex and extended medium range order of very low symmetry (see below) and is probably not relevant to the SiPOHgel structure, as we will show below.

\subsection{NMR spectra}


These are shown in Figure 7 (a) and (b). The sharp spectral lines for ${ }^{1} \mathrm{H}$ and ${ }^{31} \mathrm{P}$ resonances indicate liquid-like mobility in this flexible solid material. The fact that the resonances in both the ${ }^{1} \mathrm{H}$ and ${ }^{31} \mathrm{P}$ NMR spectra are essentially those of phosphoric acid $\mathrm{H}_{3} \mathrm{PO}_{4}$, strongly indicates that the preparation procedure has caused a total reorganization of the original "SiPOH" solid acid, (which has silicon in sixfold coordination, see Figure $7(c)$ ), to produce a phosphoric acid gel for which the supporting structure must be a silica or silicophosphate net. The latter can be excluded by the solid state NMR spectra discussed below. However, the fact that the Si:P ratio must remain at the original value of 1:4, implies that the gel must be a very "tight" one. The length scales for silicate and $\mathrm{H}_{3} \mathrm{PO}_{4}$ components must remain comparable to maintain the $1: 4$ composition ratio.

A structure, in which the $\mathrm{P}$ content is realized in $\mathrm{H}_{3} \mathrm{PO}_{4}$ molecular form, would be consistent with the finding of Figure 2 that the thermal stability limit for high conductivity is around $150^{\circ} \mathrm{C}$, the same as that attributed to phosphoric acid. That the supporting structure contains silicon in its normal 4-coordinated state (as opposed to the 6-coordinated state of ambient temperature $\mathrm{SiPOH}$ ), is shown by the (magic angle spinning) solid state NMR spectrum for Si (in its natural abundance) in Figure 7(c). The resonance is found at -115 ppm referenced to the standard TMS, (but using solid tetrakis(trimethylsilyl)silane (TTSS) as external secondary reference (TTSS $-9.8 \mathrm{ppm}$ )). A chemical shift of $-115 \mathrm{ppm}$ is at the downfield extreme of the chemical shift range for $\left[\mathrm{SiO}_{4}\right]$ groups, indeed it is some $5 \mathrm{ppm}$ beyond the average for the $\mathrm{Q}_{4}$ grouping given for silicate minerals by Magi et al[44] and by various studies of the silica polymorphs, cristobalite, tridymite and quartz. 


\section{Figure 7 here}

To find ${ }^{29} \mathrm{Si}$ spectra more downfield than the $-110 \mathrm{ppm}$ of the common $\mathrm{SiO}_{2}$ polymorphs, one must turn to pure silicas of zeolitic form. For instance, the aluminum-free form of MCM-41 has three main ${ }^{29} \mathrm{Si}$ resonances at $-111.3,-112.7$ and $-115.3 \mathrm{ppm}[45]$. Since SiPOHgel, in each of its preparations, has a broad resonance with the same average value of -115 ppm, see Figure 8, we conclude that our material is a novel amorphous form of zeolitic silica, perhaps with even larger pores than MCM-41, occluding $\mathrm{H}_{3} \mathrm{PO}_{4}$ molecules. Such structures are characterized by very low frequency vibrational modes that, at high temperatures $\left(\sim 800^{\circ} \mathrm{C}\right)$, lead to collapse to denser more stable forms[46]. However they are indefinitely stable at moderate temperatures. Their formation was probably supported by $\mathrm{H}_{3} \mathrm{PO}_{4}$ molecules acting as templates. As established by Dove[47] and others[46, 48], these open silicate structures are inherently "floppy" even though fully connected - which might account for the important flexibility that the membranes exhibit. Finally, a solid state NMR spectrum of ${ }^{31} \mathrm{P}$ (not shown) produced no important new lines (a barely detectable resonance at $-11 \mathrm{ppm}$ is not considered significant). Thus all Si-O-P bonds have been broken in the solution -gelation process.

\section{Figure 8 here}


Since, by preparation, there are $4 \mathrm{P}$ for every $\mathrm{Si}$, and since the number of the $\mathrm{H}_{3} \mathrm{PO}_{4}$ molecules grows as the cube of the dimension of any nanodomain, the dispersion of $\mathrm{H}_{3} \mathrm{PO}_{4}$ in the silica network must be nanoscopic, or at least highly ramified. It is plausible that the $\mathrm{H}_{3} \mathrm{PO}_{4}$ molecules might rotate freely within the zeolitic pores to pass their protons along without actually diffusing themselves - an ideal condition. Pulsed field gradient ${ }^{31} \mathrm{P}$ NMR studies of self-diffusion should help establish the extent to which such desirable behavior might characterize the new membrane.

\subsection{XRD studies of calcined and amorphous structures.}

4.2.1 Calcined structures. The XRD patterns of the calcined SiPOH and SiPOHgel are of possible interest in relation to the complex crystalline phases in this system, but are deemed irrelevant to the discussion of SiPOHgel, so are placed in the supporting information.

\subsubsection{SiPOHgel}

The XRD of SiPOHgel, shown in the SI, is simple and unambiguous. The similarity to the XRD of powdered dry silica gel, taken on the same diffraction equipment, is striking (see SI.2). It is different and less complex than that of hydrated silica gel. This leaves little doubt that the material we are investigating is a fully connected amorphous silica network, with zeolite-like nanopore distributions of sufficiently floppy character to account for its 
flexible character. Occluded within the gel, and stabilizing its structure, there is evidently a uniform distribution of essentially pure phosphoric acid.

While this sort of structure probably does not bind the $\mathrm{H}_{3} \mathrm{PO}_{4}$ any more strongly than do the polybenzimidazole-based membrane materials that have been under intense study in recent years $[13,25,49-51]$, it should not lose $\mathrm{H}_{3} \mathrm{PO}_{4}$ any more rapidly than do these post-formation-doped membranes. The very low rates of $\mathrm{H}_{3} \mathrm{PO}_{4}$ depletion recorded by Linares et al [50] (falling rapidly to negligible under gas flow at temperatures up to $190^{\circ} \mathrm{C}$ ) , give little cause for concern and are consistent with our own favorable constant current observations Figure 6.

It might be asked, why not simply absorb $\mathrm{H}_{3} \mathrm{PO}_{4}$ into dry silica gel and use that material as the electrolyte? Apart from the fact that a material so prepared would have no flexibility, this has already been attempted in the work of Matsuda et al[19] and then abandoned. These workers found that the conductivity of the aqueous $\mathrm{H}_{3} \mathrm{PO}_{4}$-soaked silica gel faded rapidly to below $10^{-4} \mathrm{Scm}^{-1}$ on standing at $130^{\circ} \mathrm{C}$. Phosphosilicate powders compressed to disc form, with $\mathrm{P} / \mathrm{Si}$ ratios near unity behaved better, retaining their $10^{-2}$ $\mathrm{Scm}^{-1}$ conductivities over longer periods of time at the same temperature[19], but this is still far below the SiPOHgel conductivity at the same temperature seen in Figure 2. These latter studies clearly have features in common with the present study, but they evidently did not find the aqueous route to the flexible solid product that seems to have the unique properties needed for fuel cell applications, as illustrated in Figures 4 and 5.

\section{Concluding remarks.}


We have so far only prepared and tested SiPOHgels obtained by relatively lowtemperature dehydration procedures. We surmise that a more aggressive dehydration might produce a gelled form of the $>200^{\circ} \mathrm{C}$-stable liquid electrolyte on which we reported recently. While the present formulation is desirable for processes operating in the range not too far above $100^{\circ} \mathrm{C}$, an extension of the temperature range to the $>200^{\circ} \mathrm{C}$ range would have advantages for some purposes and will be the subject of future investigations.

While we are not aware of other acid gels that form by self-assembly in situ via the present process, it seems quite likely that there are analogous cases, based on the hydration of other silicooxyacids, waiting to be made. It will be interesting to determine the maximum acidity material that can be prepared in this semisolid form by the procedure we have described. Although phosphates are preferred over sulfates for fuel cell purposes because of their stability against reduction by hydrogen, there will be other purposes for which the benign confinement of a stronger acid might be very desirable.

\section{Acknowledgements.}

This work has been carried out under the auspices of the DOD-Army research office, under under Grant no. W911NF-07-1-0423 for the synthesis and fuel cell work, and to W911NF11-1-0263 for the structural analysis. We appreciate much valuable advice given by Don Gervasio during the development of our fuel cell interests. He also provided the design of the fuel cell of Figure 3 which was used in previous joint publications[14, 52].

\section{References}


[1] K. D. Kreuer, J. Membrane Science 185 (2001) 29.

[2] S. J. Peighambardoust, S. Rowshanzamir, and M. Amjadi, Int. J. Hydrogen Energy 35 (2010) 9349.

[3] H.-W. Zhang and P. K. Shen, Chemical Reviews 112 (2012) 2780-2832

[4] L. Ghassemzadeh, K.-D. Kreuer, J. Maier, and K. Müller, J. Phys. Chem C 114 (2010) 14635.

[5] E. Endoh, S. Terezono, H. Widjada, and Y. Talimoto, JESS Lett. 7 (2004) A209.

[6] S. Feng and G. A. Voth, J. Phys. Chem. B 115 (2011) 5903.

[7] N. Asano, M. Aoki, S. Suzuki, K. Miyatake, H. Uchida, and M. Watanabe, J. Amer. Chem. Soc. 128, (2006) 1762.

[8] M. Ji and Z. Wei, Energies 2 (2009) 1057.

[9] Y. F. Zhai, H. Zhang, Y. Zhang, and D. A. Xing, J. Power Sources 169 (2007) 259

[10] D. Aili, M. K. Hansen, C. Pan, Q. Li, E. Christensen, J. O. Jensen, and N. J. Bjerrum, Int. J. Hydrogen Energy 36 (2011) 6985.

[11] H. Tang, Z.-H. Wan, M. Pan, and A. P. Jiang, Electrochemistry Communications 9 (2007) 2003.

[12] S.-H. Kwak, T.-H. Yang, C.-S. Kim, and K. H. Yoon, Solid State Ionics 160 (2003) 309.

[13] Q. Li, J. O. Jensen, R. F. Savinelli, and N. J. Bjerrum, Prog. Polymer Sci. 34 (2009) 449.

[14] J.-P. Belieres, D. Gervasio, and C. A. Angell, Chem. Commun. (Cambridge) (2006) 4799.

[15] M. A. B. H. Susan, A. Noda, S. Mitsushima, and M. Watanabe, Chemical Communications (2003) 938.

[16] S.-Y. Lee, T. Yasuda, and M. Watanabe, J. Power Sources 195 (2010) 5909.

[17] Y. I. Park, . Kim, J.D., Naga, M. , J. Mater. Sci. Lett. 19 (2000) 2251.

[18] I. N. Tsvetkova, Shilova, O.A., Voronkov, M.G., Gomza, Yu.P., Sukhoy, K. M. , Glass Phys. Chem. 34 (2008) 68.

[19] A. Matsuda, T. Kanzaki, K. Tadanaga, M. Tatsumisago, and T. Minami, Solid State Ionics 154-155 (2002) 687.

[20] H.-W. Zhang and P. K. Shen, Chemical Reviews 112 (2012) 2780-2832.

[21] M. Kato, W. Sakamoto, and T. Yogo, J. Membr. Science, 303 (2007) 43. 
[22] J. Zeng, B. He, K. Lamb, R. De Marco, P. K. Shen, and S. P. Jiang, ACS Appl. Mater. Interfaces 5 (2013) 11240-11248.

[23] Y. Ansari, J. C. Tucker, and C. A. Angell, J. Power Sources 237 (2013) 47.

[24] Y. Ansari, T. G. Tucker, and C. A. Angell, Provisional Patent application 2012 (2012)

[25] M.-Q. Li and K. Scott, Electrochim. Acta 55 (2010) 212.

[26] S. H. Chung, S. Bajue, and S. G. Greenbaum, J. Chem. Phys. 112 (2000) 8515.

[27] L. Vilciauskas, M. E. Tuckerman, G. Bester, S. J. Paddison, and K. D. Kreuer, Nature Chem. 4 (2012) 462.

[28] T. Dippel, K. D. Kreuer, J. C. Lasse`gues, and D. Rodriguez, Solid State Ionics 61 (1993) 41.

[29] C. A. Angell, Chemical Reviews 90 (1990) 523.

[30] D. M. Bernardi, J. Electrochem. Soc. 137 (1990) 3344.

[31] T. E. Springer, Zawodzinski, T.A., Gottesfeld, S., J. Electrochem. Soc. 138 (1991) 2334.

[32] V. Bernardi D.M., M. W., J. Electrochem. Soc. 139 (1992) 2477.

[33] R. Mosdale, Srinivasan, S., Electrochim. Acta. 40 (1995) 413.

[34] T. Okada, Xie, G., Tanabe, Y., J. Electroanal. Chem. 413 (1996) 49.

[35] J. St-Pierre, Wilkinson, D.P., Knights, S., Bos, M., J. New Mater. Electrochem. Syst. 3 (2000) 99.

[36] Z. Zhang, Martin, J., Wu, J., Wang, H., Promislow, K., Balcom, B.J., J. Magn. Reson. Im. 193 (2008) 259.

[37] M. Ji, Wei, Z., Energies 2 (2009) 1057.

[38] W. Liu, K. Ruth, and G. Rusch, J. New Mater. Electrochem. Syst. 4 (2001) 227.

[39] J. Thomson, Ph. D. Thesis, Arizona State University (2011)

[40] E. Tsuchida, J. Phys. Soc. Jpn 75 (2006) 054801.

[41] T. R. Krawietz, P. Lin, K. E. Lotterhos, P. D. Torres, D. H. Barich, A. Clearfield, and J. F. Haw, J. Am. Chem. Soc. 120 ( 1998) 8502.

[42] M. Elisa, B. A. Sava, A. Volceanov, R. C. C. Monteiro, E. Alves, N. Franco, F. A. CostaOliveira, H. Fernandes, and M. C. Ferro, J. Non-Cryst. Solids 356 (2010) 495.

[43] S. Jähnigen, E. Brendler, U. Böhme, and E. Kroke, Chem. Commun. 48 (2012,) 7675.

[44] M. Magi, E. Lippmaa, A. Samoson, G. Engelhardt, and A.-R. Grimmer, J. Phys. Chem. 88 (1984) 1518. 
[45] S. Inagaki, I. Kawamura, Y. Sasaki, K. Yoshida, Y. Kubota, and A. Naito, Phys. Chem. Chem. Phys. 15 (2013) 13523.

[46] G. N. Greaves, F. Meneau, O. Majerus, D. G. Jones, and J. Taylor, Science 308 (2005) 1299.

[47] M. T. Dove, M. J. Harris, A. C. Hannon, J. M. Parker, I. P. Swainson, and M. Gambhir, Phys. Rev. Lett. 78 (1997) 1070.

[48] M. F. Thorpe and P. M. Duxbury, "Rigidity Theory and Applications", Ed. M. F. Thorpe and P.M. Duxbury (Kluwer Academic/Plenum Publishers, New York, (1999)

[49] S. Matar, A. Higier, and H.-T. Liu, J. Power Sources, 195 (2010) 181.

[50] J. J. Linares, C. Sanches, V. A. Paganin, and E. R. Gonz’alez, J. Electrochem. Soc. 159 (2012) F194.

[51] L. Xiao, H.-W. Zhang, T. Jana, E. Scanlon, R. Chen, E.-W. Choe, L. S. Ramanathan, S. Yu, and B. C. Benicewicz, Fuel Cells 5 (2005) 287.

[52] J. Thomson, P. Dunn, L. Holmes, J.-P. Belieres, C. A. Angell, and D. Gervasio, ECS Trans 13 (2008) 21.

\section{FIGURE CAPTIONS}

Figure 1. (a) Drying curve showing the loss of $90 \%$ of the initial gel mass (obtained by dissolution of siphoric acid in water), during vacuum drying with periodic weight recording. Constant mass is reached after about $15 \mathrm{hr}$, as vapor pressure approaches zero.

(b) button of flexible solid (here called SiPOHgel) obtained by the described procedure.

(c) preparation of the fibre glass reinforced disc for fuel cell membrane. 1" fibre glass filter disc is immersed in initial pre-gel solution and incorporated in the polymer as the water is evaporated off. (Vial shown upside down after partial drying). (d) Disc impregnated with SiPOHgel is removed, and chosen diameter disc punched out (shown held by tweezers).

Figure 2. The conductivity of SiPOHgel at temperatures up to $150^{\circ} \mathrm{C}$, compared with those of Nafion samples from different authors (identified in the legend) using high hydration, pressure and humidification. Solid circles for SiPOHgel are for points obtained during heating, small open circles are obtained during cooling, to confirm high temperature stability. Data for $\mathrm{H}_{3} \mathrm{PO}_{4} 100 \%$, (this work) and $\mathrm{H}_{3} \mathrm{PO}_{4}$ imbibed in Nafion-PBI[25], are included for comparison. 
Figure 3. Exploded view of the Teflon sandwich type cell used for fuel cell testing.

Not included in the diagram are gaskets between membrane and E-tek electrode.

Figure 4: Tafel plots (IR corrected) for fuel cell performance using the pristine SiPOHgel (lower curves with poor OCV) and the fiberglass- reinforced and dimensionally regular SiPOHgel membrane (upper curves). The experiments used identical Teflon fuel cell blocks with identical E-Tek electrodes. Different gaskets allowed for active areas of $0.5 \mathrm{~cm}^{2}$ and $0.8 \mathrm{~cm}^{2}$. Flow rates of $\mathrm{H}_{2}$ for each electrolyte at each temperature are included in legends. Flow rate for $\mathrm{O}_{2}=2 \times$ flow rate for $\mathrm{H}_{2}$. The dotted lines at the top of the diagram are the thermodynamic OCV's for the temperatures indicated.

Figure 5. Polarization curves (linear current and no IR correction), and the corresponding power densities, for the pristine SiPOHgel membrane $\left(\right.$ at $152^{\circ} \mathrm{C}$ ) and the fiberglass reinforced $2 \mathrm{~mm}$ thick SiPOHgel membrane (at $124^{\circ} \mathrm{C}$ and $154^{\circ} \mathrm{C}$ ). Note the power maximum of $202 \mathrm{mWcm}^{-2}$ obtained at $0.4 \mathrm{~V}$ for the fiberglass-reinforced membrane at $154^{\circ} \mathrm{C}$.

Figure 6. Degradation testing of the SiPOHgel-K membrane at $120^{\circ} \mathrm{C}$ and $50 \mathrm{mAcm}^{-2}$, and at the current of maximum power at $150^{\circ} \mathrm{C}$. Comparison is made with an earlier study [39] made using the same cell with the same (Etek) electrodes, but with liquid phosphoric acid (85\% by wt), and with the finding of Li and Scott[25] on their high performance PA in Nafion-PBI membrane under the same conditions $\left(150^{\circ} \mathrm{C}\right.$ and maximum power $)$.

Figure 7. (a) and (b). The ${ }^{1} \mathrm{H}$ and ${ }^{31} \mathrm{P}$ spectra of the flexible gel of Figure 1 (b) showing sharp resonances at $9.5 \mathrm{ppm}$ relative to TMS, and at 0.0 relative to $\mathrm{H}_{3} \mathrm{PO}_{4}$. The liquid-like sharpness of the lines, despite measurement in a standard liquid state spectrometer, is consistent with the observation of liquid-like conductivities in Figure 2. 
(c) Solid state NMR spectrum of ${ }^{29} \mathrm{Si}$ (natural abundance) in the siphoric acid $(\mathrm{SiPOH})$ precursor to the formation of the polymer gel of Figure 1(b), showing a sharp resonance at $-210 \mathrm{ppm}$ that establishes the presence of silicon in six coordination in $\mathrm{SiPOH}$, and the SiPOHgel material of the present contribution, showing a resonance at $\sim-115 \mathrm{ppm}$ that is at the outer edge of the range known for silicon that is four-coordinated to bridging oxygens in tetrahedral silicate networks

\section{Figure 8.}

(a) Comparison of ${ }^{29} \mathrm{Si}$ MAS-NMR spectra for SiPOHgel, and SiPOHgel-K, with nanosphere $\mathrm{SiO}_{2}$ showing the higher frequency resonances of the SiPOHgels.

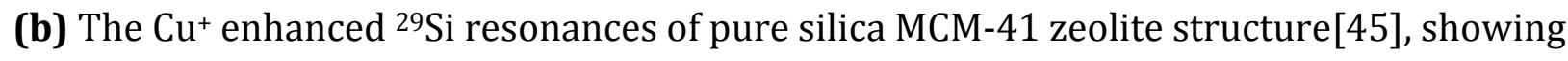
two new resonances in the domain of the SiPOHgel spectra. 


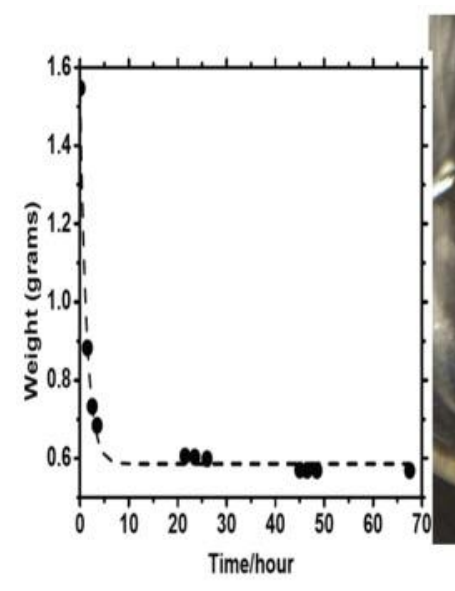

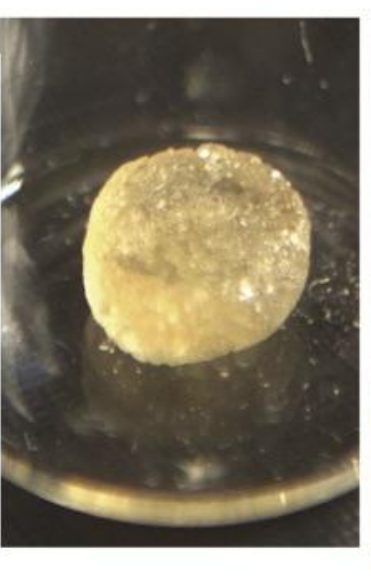

(b)

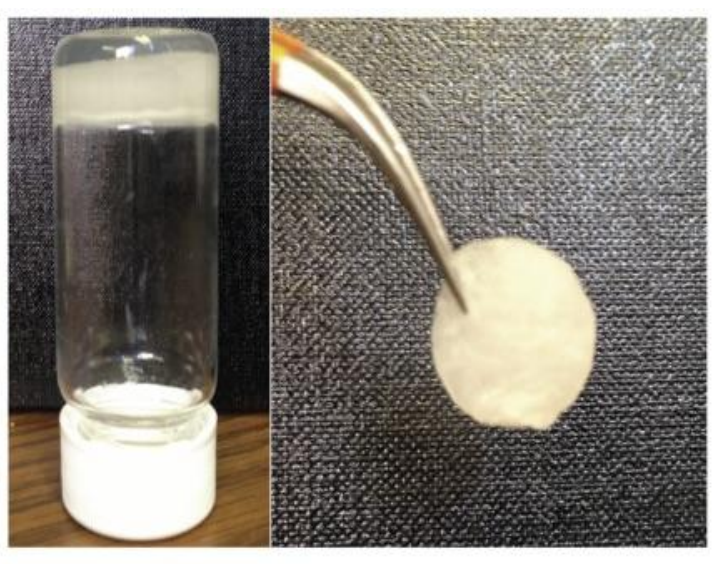

(c)

(d) 


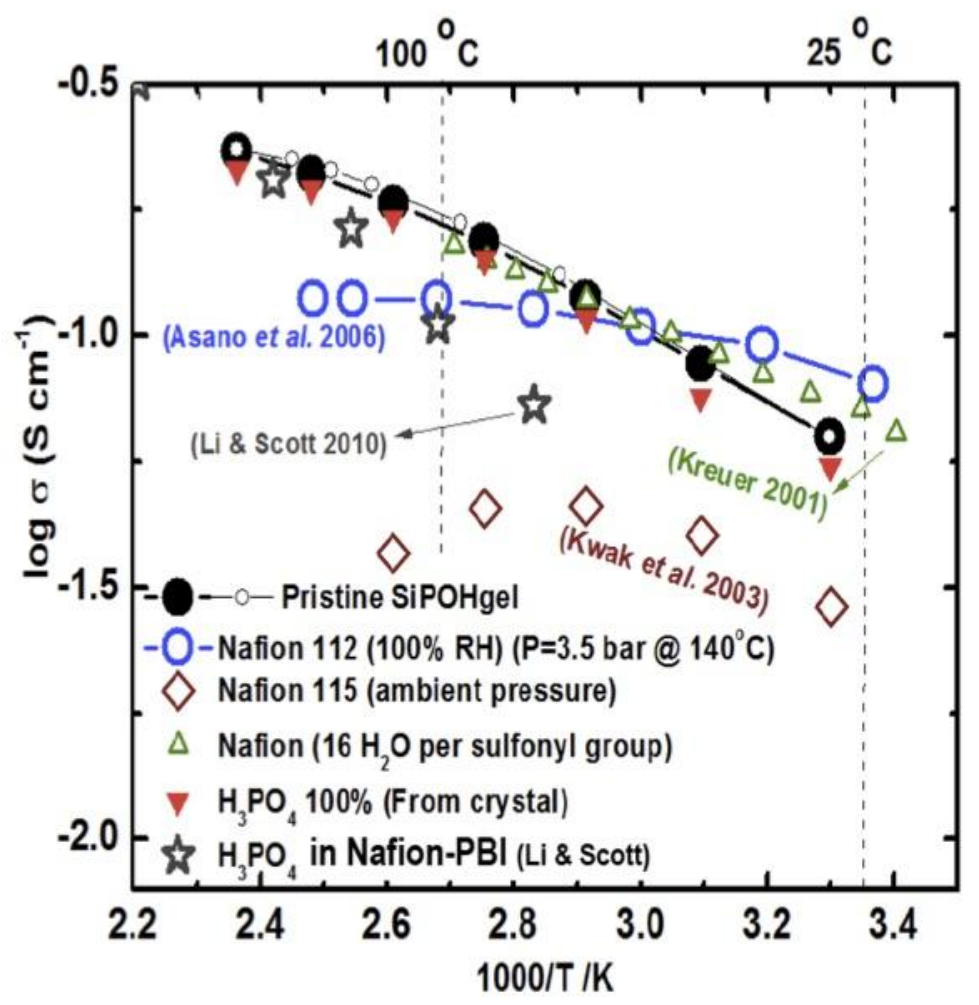




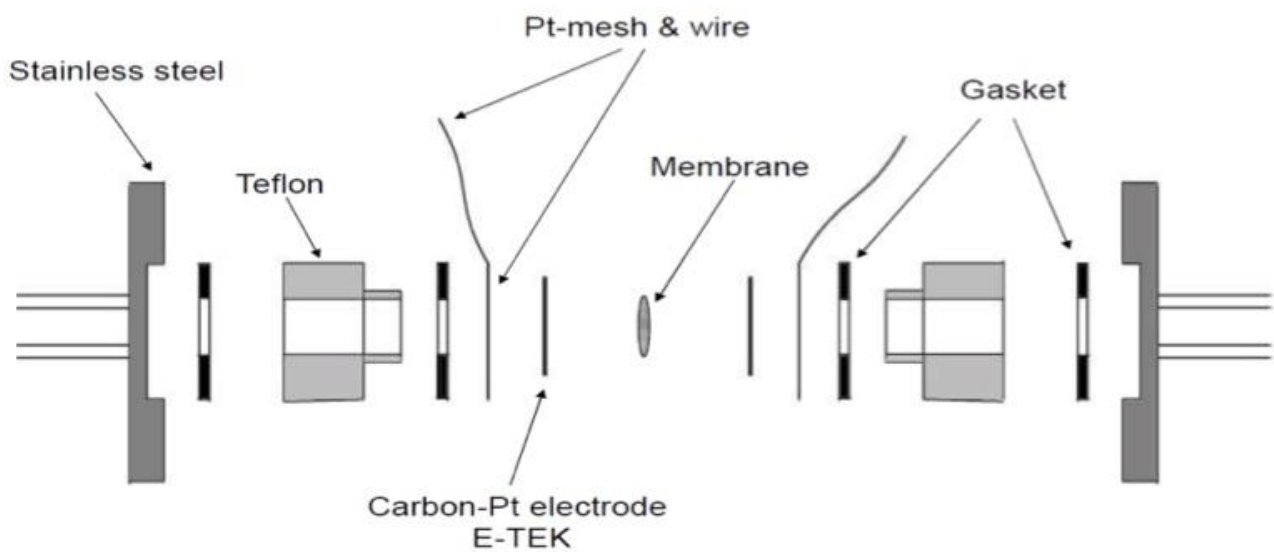




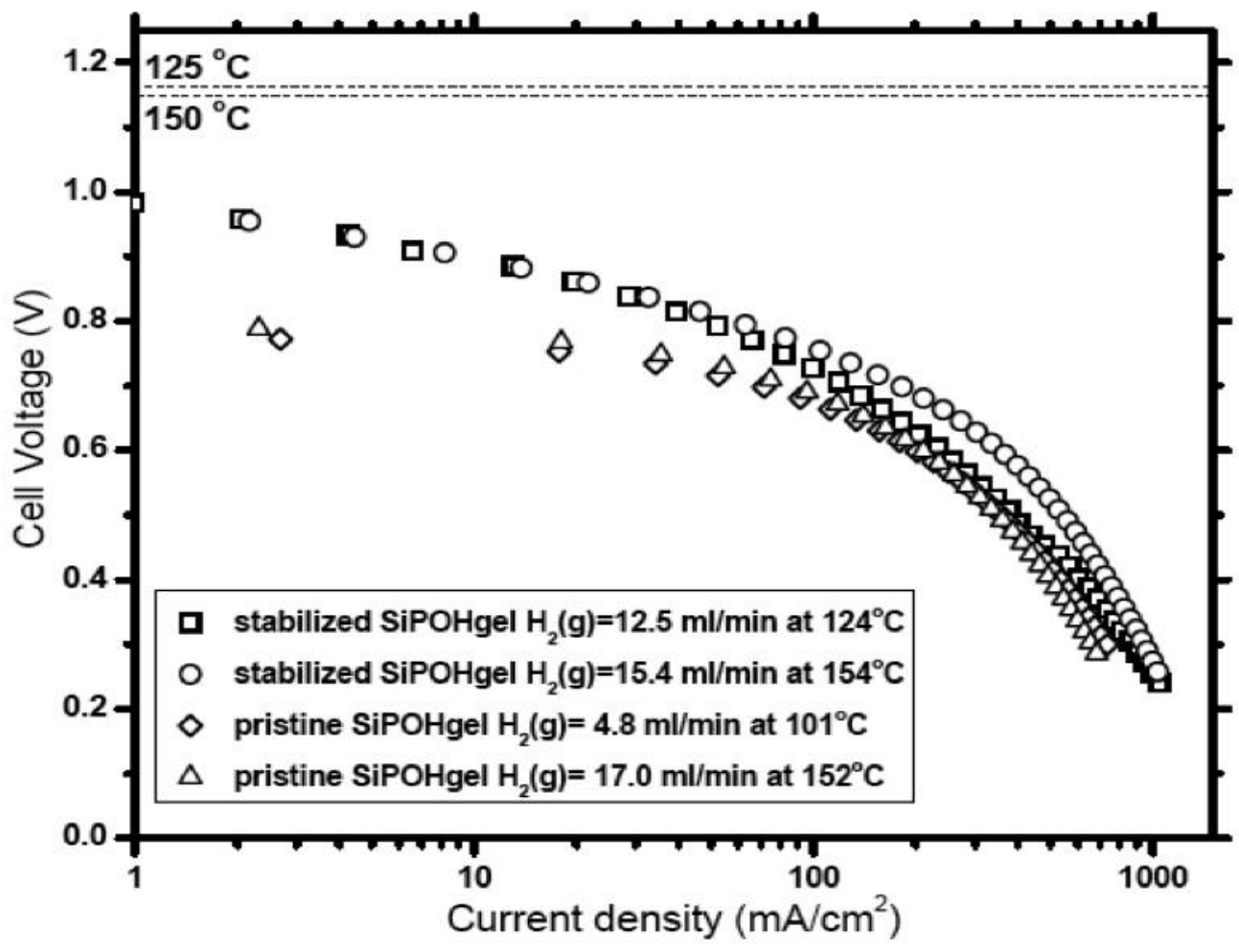




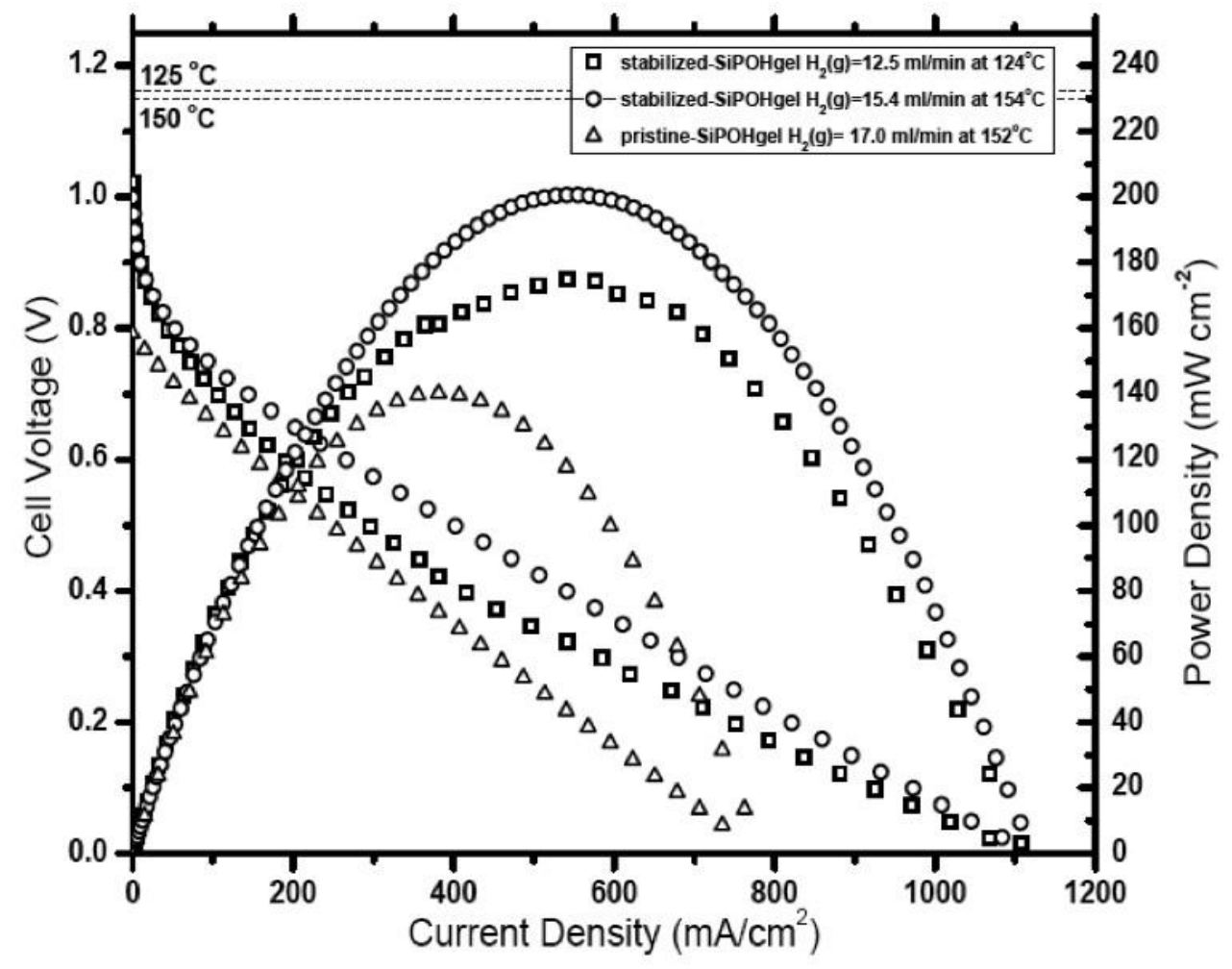




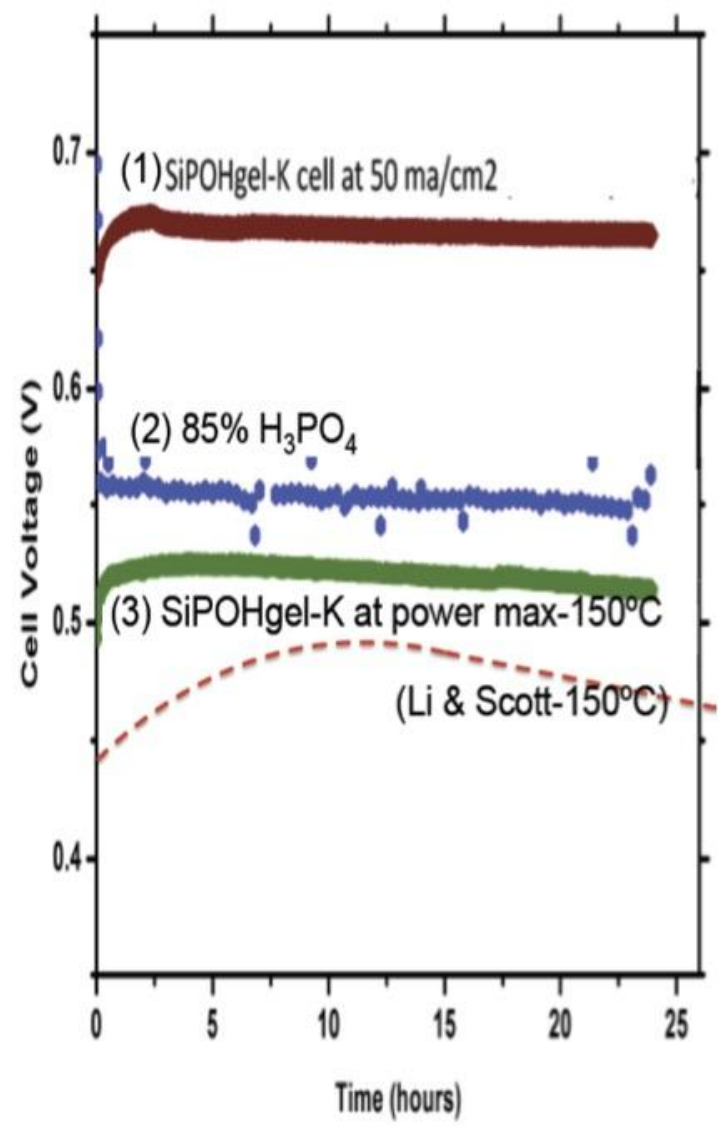



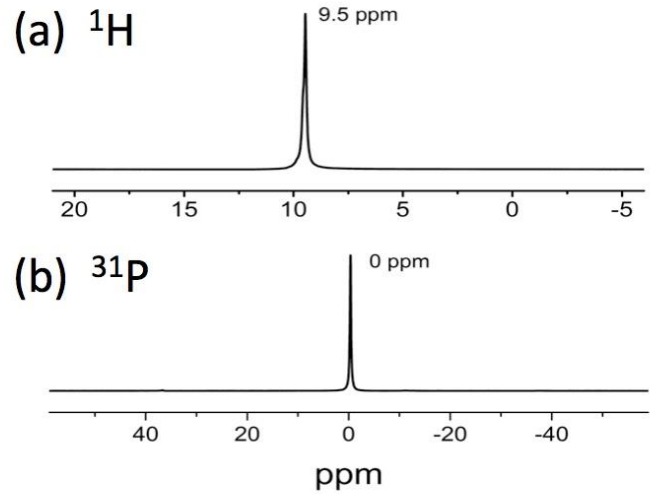

(c) ${ }^{29} \mathrm{Si}$
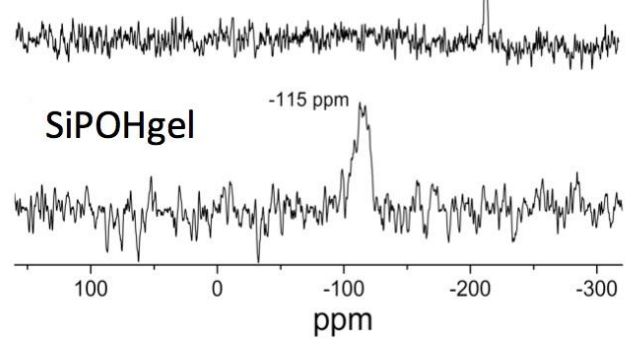


\section{Ansari et al SiPOHgel Figure 8}
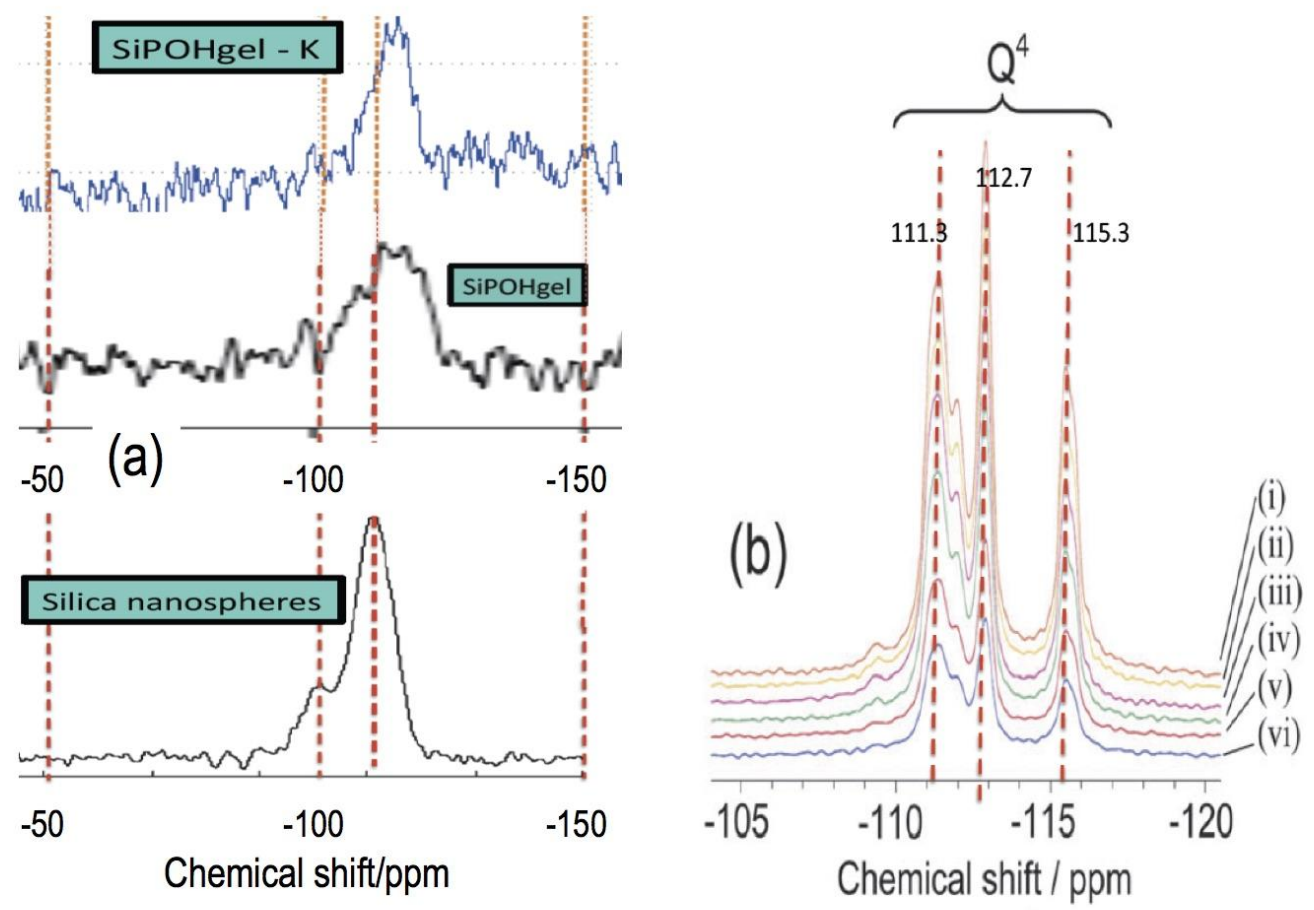